\title{
Is Creative Commons a Panacea for \\ Managing Digital Humanities Intellectual Property Rights?
}

Yi Ding

\section{ABSTRACT}

Digital humanities is an academic field applying computational methods to explore topics and questions in the humanities field. Digital humanities projects, as a result, consist of a variety of creative works different from those in traditional humanities disciplines. Born to provide free, simple ways to grant permissions to creative works, Creative Commons (CC) licenses have become top options for many digital humanities scholars to handle intellectual property rights in the US. However, there are limitations of using CC licenses that are sometimes unknown by scholars and academic librarians. By analyzing case studies and influential lawsuits about intellectual property rights in the digital age, this article advocates for a critical perspective of copyright education and provides academic librarians with specific recommendations about advising digital humanities scholars to use CC licenses with four limitations in mind: 1) the pitfall of a free license; 2) the risk of irrevocability; 3) the ambiguity of NonCommercial and NonDerivative licenses; 4) the dilemma of ShareAlike and the open movement.

\section{INTRODUCTION}

Along with an increasing number of digital scholarships, open access became a preferred, more affordable model for scholarly communication in the US. ${ }^{1}$ In particular, digital humanists envision a sharing culture that digital contents and tools can be widely distributed through open access licenses. ${ }^{2}$ Creative Commons (CC) licenses, with their promise to provide simple ways to grant permissions to creative works, became top options for many digital humanities to handle intellectual property rights in the US.

However, Creative Commons is not a panacea for managing the intellectual property rights of digital scholarship. Digital humanities projects usually consist of complicated components and their intellectual property rights involve various licenses and stakeholders. With misunderstandings of intellectual property and CC licenses, many scholars are not fully aware of the implications of using CC licenses, which cannot provide legal solutions to all intellectual property rights issues. The increasingly popular application and commercialization of digital humanities projects in the US further complicate the issue.

Based on case studies and influential lawsuits involving the topic in the US, this article critically investigates the limitations of using CC licenses and recommends that academic librarians provide scholars with more sophisticated suggestions on using CC licenses as well as providing education on intellectual property rights in general.

Yi Ding (yi.ding@csun.edu) is Online Instructional Design Librarian and Affordable Learning \$olutions Co-coordinator, California State University, Northridge. 


\section{LITERATURE REVIEW}

Usually identified as rights experts, academic librarians are in a unique position to provide copyright education in the digital humanities field through consultation, instruction, and other means to faculty and students. ${ }^{3}$ Librarians sometimes position themselves as "reuse evangelists" who embrace the vision of Creative Commons by applying CC licenses as well as introducing CC licenses to the campus community through guides and webpages. ${ }^{4}$ Yet, few discussions have been brought up about the limitations of CC licenses in the library community. ${ }^{5}$ Drawing from scholarly literature from the law field and primary sources including lawsuits, websites, magazine articles, and newspaper articles involving this topic, this article intends to bring a critical perspective into the copyright education academic librarians provide by analyzing the four limitations of CC licenses in managing digital humanities projects intellectual property rights.

In the law community, scholars have examined the limitations of open licensing and Creative Commons. Katz elaborated the mismatch of the vision of Creative Commons and its licensors as well as how the incompatibility of CC licenses may result in potential detriment to the dissemination of knowledge. ${ }^{6}$ Scholars later have referred to Katz in extensive discussions of the limitations of CC licenses in different realms of copyrighted works. For example, Johnson investigated several limitations of CC licenses for entertainment media, including those with ShareAlike, NonCommercial, and NonDerivative licenses. ${ }^{7}$ Lukoseviciene acknowledged the efficiency of CC licenses while pointing out its limitation in ensuring equity in a sharing culture. ${ }^{8}$ When discussing the problems of CC licenses in data sharing, Khayyat and Bannister echoed Katz's critique on the limitation of CC licenses in combining copyrighted works with different types of licenses. ${ }^{9}$

Scholars have also addressed problems related to intellectual property rights other than copyright when applying CC licenses. For example, Hietnanen discussed the problems of license interpretation and concluded that although CC licenses are useful for "low value - high volume licensing," it fails to address some important intellectual property rights including privacy and moral rights. ${ }^{10}$ Burger demonstrated how CC commercial licenses have encouraged publicity right infringement in several cases. ${ }^{11}$

Nevertheless, none of the above scholars discussed the implication of the limitations of CC licenses in digital scholarship. To solve the problem of excessive open-source licenses, Gomulkiewicz suggested a license-selection "wizard" modeling what Creative Commons offers, which demonstrates the limitation of CC licenses in managing the intellectual property rights of codes, a common component of many digital humanities projects. ${ }^{12}$ This article does not aim to conduct a comprehensive assessment of pitfalls of CC licenses in digital scholarship or make legal recommendations to manage the intellectual property rights of digital humanities projects. Rather, it discusses the four limitations of CC licenses that are usually overlooked but essential for academic librarians to educate patrons in the digital humanities field. With the development of the digital humanities field and more students involved in it, academic librarians should educate both faculty scholars and emerging scholars about implications of applying CC licenses. ${ }^{13}$ 


\section{FOUR LIMITATIONS OF CC LICENSES}

\section{Is Creative Commons Really Free?-The Pitfall of a Free License}

One major reason that scholars and institutions are using CC licenses is the ease of applying them to creative works. The Directory of Open Access Journals (DOAJ), which is regarded as "both an important mode of discovery and marker of legitimacy within the world of open access publishing," now recommends CC licenses as a best practice. ${ }^{14}$ DOAJ explicitly encourages scholars to use Creative Commons' "simple and easy" license chooser tool. Indeed, the Creative Commons website provides scholars and institutions a very user-friendly way to select and apply a license to copyrightable works. ${ }^{15}$ Anyone can place a CC license on a work by copying and pasting from its website. However, this oversimplified process of handling intellectual property rights of creative works may mislead both copyright owners and copyrighted works users to overlook pitfalls of this free license, including unintentional copyright and other intellectual property rights infringements.

More specifically, one prominent legal formality of CC licenses is that licensees do not need to pay to register with Creative Commons to apply a CC license. As indicated by Creative Commons website, a CC license is legally valid as soon as a user applies it to any material the user has the legal right to license. Creative Commons also does not "require registration of the work with a national copyright agency."16

While copyright protection is automatic the moment a work is created and "fixed in a tangible form," there are various advantages to register copyrighted works through the United States Copyright Office to establish a public record of the copyright claim. ${ }^{17}$ One foremost important advantage of copyright registration is that copyright owners can file an infringement suit of works of U.S. origin in court. Actually, filing a registration before or within five years of publishing a work will actually put the copyright owner in a stronger position in court to validate the copyright. ${ }^{18}$ Additionally, copyright registration enables one to get awarded statutory damages and attorney's fees and to gain protection against the importation of infringing copies. ${ }^{19}$

The emphasis on a free-to-use license along with the lack of clarification of the functions of copyright registration on the website of Creative Commons may not only mislead scholars to ignore important legal formalities within the copyright law, but also increase the abuse of original materials by stakeholders such as predatory publishers. One example is how the Integrated Study of Marine Mammals repackaged existing articles taking advantage of the Creative Commons licenses used by PLOS ONE, which has been publishing articles on digital humanities. ${ }^{20}$

The oversimplified process of using CC licenses advocated by Creative Commons website may also prevent licensors from double-checking or clarifying if they have the legal right to license a work. In 2013, Persephone Magazine, which used an image with a Creative Commons license, was later sued for $\$ 1,500$ for using it. It turned out the photo did not belong to the person who uploaded it with a CC license, which led to 73 companies who used it being sued. Persephone Magazine claimed that $\$ 1,500$ was more than its entire advertising revenue for the year and it had to ask its users to donate just to keep the site going. ${ }^{21}$

Therefore, scholars of digital humanities projects, which usually include different types of content such as artworks and photographs, should be wary of using CC licensed images. Otherwise, a freely available license might end up costing a scholar unexpected money and energy. In the 
meantime, when deciding to put their projects under CC licenses or to publish their works in a journal that requires CC licenses, scholars should also be reminded to make accurate and clear copyright statements to prevent innocent infringements of other copyright owners' works. For example, a team of art historians who create an online map of architectures in Ancient China are very likely to use and critique other people's images in digital projects under fair use. These digital humanists should cite image sources and clarify the scope of the CC license that they apply to their project.

It is understandable that in order to promote an open, sharing culture, the application of a CC license is intentionally designed to be simple and free by Creative Commons to fulfill its mission. However, the misuse of a free license can lead to false licenses and more innocent infringements and ultimately costs. Academic librarians should become aware of these pitfalls and provide more in-depth training on CC licenses to scholars, especially by collaborating with campus centers of digital humanities or language and literature faculty as well as other institutional research support departments as suggested by Fraser and Arnhem. ${ }^{22}$

\section{Is Creative Commons Really Safe?-The Risk of Irrevocability}

Similar to the pitfall of inaccurate licenses, the irrevocability of CC licenses can also be problematic. A "revocable" license is one that can be terminated by the licensor at any time during the term of the license agreement. An "irrevocable" license, on the other hand, cannot be terminated if there is no breach. All CC licenses are irrevocable. ${ }^{23}$ Licenses and contracts usually have effective date of termination and even if they don't have one, most courts hold that simple, nonexclusive licenses with unspecified durations that are silent on revocability are revocable at will. ${ }^{24}$ As a result, the irrevocability of CC licenses can be easily overlooked by CC licensors. This means that while in traditional academic publishing and other means of the dissemination of research, scholarly, and creative output, a scholar will be able to revise the copyright agreement he or she has established with a publisher or a scholarly communication venue due to the usually clear rules on termination dates and revocability, it is impossible to revoke a CC license. This discrepancy of the revocability between traditional copyright agreements and CC licenses may put copyright owners at disadvantage especially because many of them apply noncommercial CC licenses. Copyright experts have warned scholars to keep in mind that once a "nonexclusive license," which CC noncommercial licenses are, has been chosen to grant one's work, the scholar has lost potential opportunities to "license the same work on an exclusive basis," which is the case in the commercialization of a digital humanities work. ${ }^{25}$

We can understand this pitfall of the irrevocability of CC licenses in a case in late 2014. A plan by Yahoo to begin selling prints of images uploaded to Flickr was met with anger by users, even though Yahoo only used photos with Creative Commons licenses that explicitly allowed commercial uses. Although Yahoo's use of CC licensed works was legal, users who initially applied CC licenses with commercial use would not have wanted the company making canvas prints from the photos they posted to Flickr to make money. ${ }^{26}$ Should these copyright owners understand better the irrevocability of CC licenses, they might have chosen a different type of CC license with caution. Bill of Rights, a community of people advocating for protecting the intellectual property rights of artists, even called this kind of commercial use "abuse."27 Although most digital scholars, like those Flickr users, have a genuine interest in making their works available to as many people as possible, it can be hard to gauge their reactions to all unforeseen outcomes of applying CC licenses to their works. Therefore, scholars need more institutional support and education to 
become aware of the irrevocability of CC licenses when managing the intellectual property rights of their digital scholarship projects.

This institutional awareness-building is especially important because of the lack of support from Creative Commons. Irrevocability is listed in the "Considerations before licensing" section on the website of Creative Commons. However, scholars may easily overlook the irrevocability feature of CC licenses due to two reasons. First, the 6,500-plus-word "Considerations before licensing" section is not a mandatory step to go through for licensors. It is simply a clickable link from the "Choose a license" webpage of Creative Commons. ${ }^{28}$ Second, although every CC license consists of three layers, the lawyer-readable legal code, the human-readable deed, and the machine-readable code, the irrevocability of CC licenses can be easily buried in those texts when a layperson without any experience or training of CC license look for the simplest way to promote and expose their works as much as possible. ${ }^{29}$

Some may suggest putting everything under noncommercial use. However, it is not an option for some platforms and is even discouraged by some digital scholarship repositories. For example, the Open Access Scholarly Publishers Association strongly encourages the use of the CC-BY license wherever possible. ${ }^{30}$ The rationale behind the recommendation is the hope to make scientific findings available for innovations as well as to make open-access journals sustainable with sufficient profit to operate. Driven by the same objectives, CC-BY has become the gold standard for OA publishing. The three largest OA publishers (BioMed Central, PLOS, and Hindawi) all use this license. ${ }^{31}$ In particular, the often multimedia and viable characteristics of digital humanities projects can expose them to even more infringement issues in the future.

One example of this is RomeLab, a project focusing on the recreation of the Roman Forum, and its website is made up of multiple separate components. The project's website is constructed with the Drupal content management system, and is integrated with a 3D virtual world component, where users can access the RomeLab website and walk through the virtual space of Rome itself. RomeLab is currently under a Creative Commons Attribution-NonCommercial License. As a project funded by the Mellon Foundation, RomeLab is required to offer "nonexclusive, royalty-free, worldwide, perpetual, irrevocable license to distribute" its data. ${ }^{32}$ However, it is never clear to the researchers creating the site how to release the data that only work within the proprietary software Unity Engine that they used to produce the virtual space and more importantly, all the 3D models and pictures. Simply putting the whole site under the Creative Commons Attribution-NonCommercial License doesn't automatically make its research data accessible by the public. In this case, the irrevocability of CC licenses further complicates the issue of CC licenses being oversimplified. Specifically, since the RomeLab website is also equipped with a chat feature and a multiplayer function, allowing multiple users to interact with each other, the project has a great potential to make profit if repurposed as a teaching tool and even an educational game in the future. Whether or not researchers of RomeLab manage to make their research data publicly available, CC licenses are not a panacea to handle conflicting data release expectations and intellectual property rights of Unity Engine and Mellon Foundation. It is therefore recommended that digital scholars consider various data types and licensing options before exclusively applying irrevocable CC licenses to their creative works.

Moreover, if the creator of RomeLab wants to produce a virtual introduction of the 3D world of the project, he should take into consideration of the limitation of CC licenses before disseminating his 
work via platforms such as YouTube. In 2014, a user found out that somebody took his drone video of Burning Man 2013 and reposted it in its entirety to YouTube under the inaccurate and misleading title "Drone's Eye View of Burning Man 2014," which earned a large number of views and advertising. ${ }^{33}$ When everyone was looking for the newest drone video of Burning Man in 2014 , the video posted by this other person received millions of views, which earned them money from YouTube advertising. The reason the user cannot sue this other person is that he originally licensed his video under CC BY license, which allows commercial use, and which unfortunately is YouTube's only CC license option. ${ }^{34}$ Had the original videographer better understood the irrevocability of CC licenses, he might have chosen a different platform to disseminate his video or at least utilized other ways to protect his copyright. Scholars would not want this kind of abuse of their original works and thus should be more cautious of the irrevocability of CC licenses.

Furthermore, YouTube and many other platforms that digital humanities scholars use to disseminate their research, scholarly, and creative work fail to provide effective functionalities and incentives to fulfill CC's attribution requirement. ${ }^{35}$ CC BY license stipulates, "If supplied, you must provide the name of the creator and attribution parties, a copyright notice, a license notice, a disclaimer notice, and a link to the material." 36 To find this piece of information on YouTube, however, someone must go to a video's landing page and first click the "SHOW MORE" text in the description below the video. Although it is clear to see the CC Attribution license with link displayed, someone must click a "View attributions" link to discover the original author's credit and source video link. The difficulty of going through different steps may impede an average YouTube user or most potential licensees of a CC-licensed digital scholarly work to learn the original creator of any content and if what they are viewing was partially or wholly created by someone else. ${ }^{37}$ Since CC licenses only provide licensees with a very general requirement to attribute, licensees are allowed to attribute "in any reasonable manner." ${ }^{38}$ With the only limitation to be "not in any way that suggests the licensor endorses you or your use," licensees are not incentivized to accurately attribute to the scholar of the original work and thus to help disseminate his or her work crediting the copyright owner. ${ }^{39}$

While users can search for registered works on the official website of United States Copyright Office, there is no way to conduct a comprehensive search for works under CC licenses. Creative Commons does not maintain a database of works distributed under CC licenses. Although there are search engines and websites for works under CC licenses, there is no way to conduct an exhaustive search. ${ }^{40}$ This can create hurdles for future licensees of a derivative work to accurately and clearly attribute the original work. One of the most important motivations of scholars to distribute their works under CC licenses is to get gain more exposure. Due to all these above limitations and others to be discussed in this paper, scholars should be more cautious of the irrevocability of CC licenses and its lack of enforcement and support system to help licensors accurately attribute the original work.

\section{Is Creative Commons Really Clear?-The Ambiguity of NonCommercial and NonDerivative Licenses NonCommercial License}

In the legal code of a CC Attribution-NonCommercial-ShareAlike License, NonCommercial is defined as "not primarily intended for or directed towards commercial advantage or monetary compensation. For purposes of this Public License, the exchange of the Licensed Material for other material subject to Copyright and Similar Rights by digital file-sharing or similar means is NonCommercial provided there is no payment of monetary compensation in connection with the 
exchange." 41 This seemingly clear statement can create some confusion and problems in the real world.

While a commercial use weighs against fair use, copyright law does not rule infringement solely on a use being commercial. In fact, it is hard to determine a use as totally noncommercial. In the case of Princeton University Press v. Michigan Document Services, Inc., Michigan Document Services (MDS) being a commercial copy shop weighs against a finding of fair use, but MDS's use being commercial is only one of the four factors in a fair-use analysis. In this case, the court held that MDS's commercial exploitation of the copyrighted works from Princeton University Press did not constitute fair use although the courts clarified the educational use was "noncommercial in nature." 42 There have been a number of cases in US copyright law where commercial uses have been ruled lawful fair use. By making commercial use a decisive factor to determine an illegal use, Creative Commons fails to specify real cases of commercial uses and thus oversimplifies the complicated copyright issues involving commercial uses that scholars should be aware of.

More specifically, many digital scholars nowadays post their articles and projects with noncommercially CC licensed images on a website, the maintenance of which is seldom free. Similar to the case of Princeton University Press v. Michigan Document Services, Inc., the educational or scholarly use of those noncommercially licensed images should be considered "noncommercial in nature." 43 However, if a digital humanist maintains a website that is subsidized partly by Google Ads or a company, the nature of the use of those noncommercially licensed images might be called into question as in the case of Princeton University Press v. Michigan Document Services, Inc. Although in both situations, the image is not "primarily intended for or directed towards commercial advantage or monetary compensation," the digital humanist may still increase the traffic of his site and thus profit from including those images on his site. ${ }^{44}$ The "different viewpoints and colliding interests" among commercial publishers, librarians, scholars, university administrators, and others may further complicate the already "ambiguous commercial nature of use" in fair use analysis that Creative Commons oversimplifies. ${ }^{45}$

The more recent case of Great Minds v. FedEx Office \& Print Services, Inc. demonstrates this ambiguity of commercial use and one use of CC NonCommercial license that is legal yet unexpected and unwanted by copyright owners. To specify, Great Minds argued that FedEx should compensate it for the money the company made from copying materials that Great Minds distributed under a CC Attribution-NonCommercial-ShareAlike 4.0 license. In an amicus brief to support FedEx Office, Creative Commons held that "entities using CC-licensed works must be free to act as entities do-including through employees and the contractors they engage in their service" and otherwise "the value of the license would be significantly diminished." 46 Creative Commons demonstrated its interpretation of a commercial use to be different from the ruling in the case Princeton University Press v. Michigan Document Services, in which the judge explicitly ruled the use to be commercial because the copyright complaint was performed on "a profitmaking basis by a commercial enterprise" and clearly forbade the contract between this enterprise and a nonprofit organization to copy and distribute copyrighted content. ${ }^{47}$ In contrast, in the case of Great Minds v. FedEx Office \& Print Services, Inc., the court held that Great Minds' nonexclusive public license, i.e. CC Attribution-NonCommercial-ShareAlike 4.0 International Public License, "unambiguously permitted school districts to engage FedEx, for a fee, to reproduce" the copyrighted content. ${ }^{48}$ Scholars should therefore be wary of the complicated process and "several areas of uncertainty" surrounding Creative Commons, which can be easily 
overlooked when applying the "simple and easy" CC licenses. ${ }^{49}$ None of the interpretations of noncommercial uses by Creative Commons are specified in the generic License Deed. Compared to more customized licenses that usually involve direct interactions between the licensor and the licensee, the free-of-charge license, CC licenses, has a long way to go to protect both licensors and licensees from infringements and financial loss. A study of noncommercial uses conducted by Creative Commons indicates that NonCommercial licenses account for "approximately two-thirds of all Creative Commons licenses associated with works available on the Internet." ${ }^{50} \mathrm{Kim}$ confirmed this popularity of CC NonCommercial licenses that "over 60 percent Flickr users prohibit commercial use or derivative work." ${ }^{51}$ As Kim elaborated and as the previous section in this paper on the irrevocability of CC licenses showcases, either commercial or noncommercial CC licenses are "likely to be detrimental to potential professional careers" of copyright owners. ${ }^{52}$ Nevertheless, as stated by Creative Commons, they do not offer legal advice. ${ }^{53}$ When providing copyright education, academic librarians should therefore remind digital scholars to be careful in using both commercial and noncommercial content and making their own content available for noncommercial purposes.

NonDerivative License

Similarly, scholars should be reminded to have a critical view of NonDerivative use of CC licenses. According to Title 17 Section 101 of the Copyright Act, a "derivative work" is a work based upon one or more preexisting works in which it may be recast, transformed, or adapted. ${ }^{54}$ However, Creative Commons used the phrase "Adapted Material" to define derivative work in the Legal Code for NonDerivative uses. ${ }^{55}$ Creative Commons has a different understanding of derivative works from what is defined by the Copyright Act in musical works. "Adapted Material is always produced where the Licensed Material is synched in timed relation with a moving image." ${ }^{56}$ This means that while using an original soundtrack in a video is not derivative work according to the Copyright Act, videos that use an ND-licensed song violate the terms of the CC license. Similar to the difference of revocability and commercial use between Creative Commons and Copyright Act as discussed earlier in this article, this different understanding of derivative work should be made aware to scholars. Specifically, when providing copyright education to scholars, academic librarians should make it clear that NonDerivative license cannot alienate the fair use rights of users and that a NonCommercial NonDerivative license does not prevent companies from using a work in a parody. ${ }^{57}$

Some licensors of CC licenses may not share Creative Commons' vision of an open, sharing culture as suggested by the prevalence of ND licenses. ${ }^{58}$ Therefore, instead of providing generic recommendation on using CC licenses, academic librarians should "balance the interests of information users and rights holders" by providing a more sophisticated and critical perspective when educating the scholarly community about the NonDerivative CC licenses. ${ }^{59}$

\section{Is Creative Commons Really Sustainable-The Dilemma of ShareAlike and Open Access} Incompatible ShareAlike Licenses

For many digital scholars, the ShareAlike term in CC licenses is intended to distribute their works more broadly and openly since a licensee is required by Creative Commons to "distribute ... [their contributions] ... under the same license as the original." ${ }^{\prime 0}$ Nevertheless, some incompatibility issues arise to prevent a more open distribution of works. For example, since the Creative Commons system offers two different ShareAlike licenses, a scholar cannot create a new derivative work combining two ShareAlike works with different terms of their respective licenses. 
It is the open and accessible nature of CC-licensed works that makes them ideal for scholars including digital humanists to collaborate on projects but ironically, the ShareAlike function can create the risk of "an intractable thicket" if incompatibilities between those licenses hinder future collaboration. ${ }^{61}$ Creative Commons does provide a series of compatible licenses, but only same licenses with differences in CC versions are considered compatible. ${ }^{62}$

\section{Against Open Access?}

These incompatibilities between certain CC licenses have been pointed out by copyright experts to limit "the future production and distribution of creative works" and even "anti-public domain."63 In 2009, the cofounder and CEO of Creative Commons, Lawrence Lessig, pointed out the perils of openness in government in his article "Against Transparency." ${ }^{64}$ Echoing his argument that "whether and how new information is used to further public objectives depends upon its incorporation into complex chains of comprehension, action, and response," this paper advocates a critical perspective of CC licenses in digital scholarship.

Apart from all the limitations of CC licenses discussed already, a more unsettling misuse of CC licenses is a failure to recognize other rights of a work beyond copyright. In 2011, the image of an underage girl, which was placed on Flickr under a CC license, was used in an advertising campaign for mobile phone services. ${ }^{65}$ Although after the lawsuit, Creative Commons CEO added a term in the Legal Deed of the latest version (4.0) of every CC license to explicitly state that other rights such as publicity, privacy, or moral rights may limit how to use the material, the case reveals the perils of openness. ${ }^{66}$ When providing copyright education, academic librarians should not only warn digital scholars of this limitation of CC licenses but also encourage them to include a statement of intellectual property rights including privacy and other rights on their digital scholarship websites to reduce abuses and innocent infringements.

\section{CONCLUSION}

Even though CC licenses are helpful for digital humanities to gain more exposure, these licenses are still being improved. Creative Commons pledged to the community to "clarify how the NC limitation works in the practical world." 67 Yet, when providing copyright consultation or partnering with digital humanity scholars, academic librarians should warn these scholars as both licensors and licensees the sophisticated implications of not only the NonCommercial license, but also other characteristics and limitations of CC licenses.

Academic librarians should introduce to digital scholars a more critical view of CC licenses by collaborating with different campus stakeholders. ${ }^{68}$ While it is recommended that academic librarians suggest digital scholars place their creative works under NonCommercial license, academic librarians should also educate them about the ambiguous definitions of commercial use as well as the possibility of commercial parody and other fair use situations. It is also recommended that academic librarians provide digital humanists with guidance on how to create intellectual property statements on their website, which should include not only copyright, but also privacy and other intellectual property rights.

Currently, a number of university libraries and nonprofit organizations, ranging from Duke University Library (http://library.duke.edu/), to Library of Congress

(https://www.flickr.com/photos/library_of_congress), and Wikipedia

(https://en.wikipedia.org/wiki/Main_Page), use CC licenses for their entire site. ${ }^{69}$ As CC license 
users, academic librarians should also be extremely careful when using CC-licensed pictures or music on the library's website. The safest way is to only use ones that are in the public domain or that are acquired by the library. Despite the use of free and simple CC licenses, academic libraries are recommended to include Terms of Use and Privacy sections on their websites to provide more detailed explanations of the function of $\mathrm{CC}$ licenses and intellectual property rights in general.

The alignment between the visions of Creative Commons, digital humanities, and "higher education as a cultural and knowledge commons" put academic librarians in a unique position to provide copyright education in the digital humanities field. ${ }^{70}$ Because of all the limitations of CC licenses, academic librarians should go beyond a simple endorsement of CC licenses and offer a more sophisticated and critical perspective when educating the scholarly community about CC licenses.

\section{NOTES}

${ }^{1}$ Amanda Hornby and Leslie Bussert, "Digital Scholarship and Scholarly Communication," University of Washington Libraries, accessed November 30, 2016, https://www.uwb.edu/getattachment/tlc/faculty/teachingresources/newmedia.

${ }^{2}$ Oya Y Rieger, "Framing Digital Humanities: The Role of New Media in Humanities Scholarship," First Monday 15, no. 10 (October 11, 2010), http://firstmonday.org/ojs/index.php/fm/article/view/3198.

${ }^{3}$ Elizabeth Joan Kelly, "Rights Instruction for Undergraduate Students: Needs, Trends, and Resources," College \& Undergraduate Libraries 25, no. 1 (2018): 1-16, https://doi.org/10.1080/10691316.2016.1275910.

${ }^{4}$ Daniel Hickey, "The Reuse Evangelist: Taking Ownership of Copyright Questions at Your Library," Reference \& User Services Quarterly 51, no. 1 (2011): 9-11; "Research Guides: Image Resources: Creative Commons Images," Creative Commons Images - Image Resources Research Guides at UCLA Library, accessed April 28, 2019, https://guides.library.ucla.edu/c.php?g=180361\&p=1185834; "Finding Public Domain \& Creative Commons Media: Images," Research Guides, accessed April 28, 2019, https://guides.library.harvard.edu/c.php?g=310751\&p=2072816. UCLA and Harvard are two good examples.

${ }^{5}$ Lewin-Lane et al., "The Search for a Service Model of Copyright Best Practices in Academic Libraries," Journal of Copyright in Education and Librarianship 2, no. 2 (2018): 1-24. Harvard. For example, when conducting a literature review of the copyright education in academic libraries to search for best practices, does not discuss any limitation of CC licenses in this article.

${ }^{6}$ Zachary Katz, "Pitfalls of Open Licensing: An Analysis of Creative Commons Licensing," Idea: The Intellectual Property Law Review 46, no. 3 (2006): 391-413.

${ }^{7}$ Eric E. Johnson, "Rethinking Sharing Licenses for Entertainment Media," Cardozo Arts \& Entertainment Law Journal 26, no. 2 (2008): 391-440. 
${ }^{8}$ Aurelija Lukoseviciene, "Beyond the Creative Commons Framework of Production and Dissemination of Knowledge," http://dx.doi.org/10.2139/ssrn.1973967.

${ }^{9}$ Mashael Khayyat and Frank Bannister, "Open Data Licensing: More than Meets the Eye," Information Polity: The International Journal of Government \& Democracy in the Information Age 20 (4): 231-52, https://doi:10.3233/IP-150357.

${ }^{10}$ Herkko Hietanen, "The Pursuit of Efficient Copyright Licensing: How Some Rights Reserved Attempts to Solve the Problems of All Rights Reserved," Lappeenranta University of Technology, 2008.

${ }^{11}$ Christa Engel Pletcher Burger, "Are Publicity Rights Gone in a Flash?: Flickr, Creative Commons, and the Commercial Use of Personal Photographs," Florida State Business Review 8 (2009): 129, https://ssrn.com/abstract=1476347.

${ }^{12}$ Robert W Gomulkiewicz, "Open Source License Proliferation: Helpful Diversity or Hopeless Confusion?" Washington University Journal of Law \& Policy 30 (2009): 261; Expanded Academic ASAP, accessed April 28, 2019, http://link.galegroup.com.libproxy.csun.edu/apps/doc/A208273638/EAIM?u=csunorthridge \&sid=EAIM \&xid=4bbf2442.

${ }^{13}$ Jacob H. Rooksby, "A Fresh Look at Copyright on Campus," Missouri Law Review (Summer 2016): 769; General OneFile, accessed April 27, 2019, http://link.galegroup.com.libproxy.csun.edu/apps/doc/A485538679/ITOF?u=csunorthridge\& sid=ITOF $\&$ xid $=1 \mathrm{f} 2822 \mathrm{f} 3$.

14 "eScholarship: Copyright \& Legal Agreements," accessed December 1, 2016, http://escholarship.org/help_copyright.html\#creative.

15 “Directory of Open Access Journals," DOAJ, accessed December 1, 2016, https://doaj.org.

16 "Frequently Asked Questions-Creative Commons," accessed December 7, 2016, https://creativecommons.org/faq/\#do-i-need-to-register-with-creative-commons-before-iobtain-a-license.

17 “Copyright in General," U.S. Copyright Office, accessed July 30, 2019, https://www.copyright.gov/help/faq/faq-general.html.

18 "Why Should I Register My Work If Copyright Protection Is Automatic?," Copyright Alliance, accessed July 28, 2019, https://copyrightalliance.org/ca_faq_post/copyright-protection-ata/.

19 "Copyright Basics," U.S. Copyright Office and Library of Congress, accessed November 30, 2016. https://www.copyright.gov/circs/circ01.pdf\#page=7.

${ }^{20}$ Phil Clapham, "Are Creative Commons Licenses Overly Permissive? The Case of a Predatory Publisher," BioScience (2018): 842-43, accessed April 20, 2019, https://doi:10.1093/biosci/biy098; Cornelius Puschmann and Marco Bastos, "How Digital Are 
the Digital Humanities? An Analysis of Two Scholarly Blogging Platforms," Plos One 10, no. 2 (2015), accessed April 20, 2019. https://doi:10.1371/journal.pone.0115035.

21 "Why Your Blog Images Are a Ticking Time Bomb," Koozai.com, accessed December 2, 2016, https://www.koozai.com/blog/content-marketing-seo/blog-sued-for-images/.

${ }^{22}$ John W. White and Heather Gilbert eds., Laying the Foundation: Digital Humanities in Academic Libraries (West Lafayette: Purdue University Press, 2016), ProQuest Ebook Central.

23 "Considerations for Licensors and Licensees-Creative Commons," accessed December 7, 2016, https://wiki.creativecommons.org/wiki/Considerations_for_licensors_and_licensees.

24 “The Terms 'Revocable' and 'Irrevocable' in License Agreements: Tips and Pitfalls," accessed December 7, 2016, http://www.sidley.com/news/the-terms-revocable-and-irrevocable-inlicense-agreements-tips-and-pitfalls-02-21-2013.

${ }^{25}$ Mark Seeley and Lois Wasoff, "Legal Aspects and Copyright-15," in Academic and Professional Publishing, edited by Robert Campbell, Ed Pentz, and Ian Borthwick (Cambridge, UK: Elsevier Ltd, 2012), 355-83.

${ }^{26}$ Douglas MacMillan, “Fight Over Yahoo's Use of Flickr Photos," Wall Street Journal, November 25, 2014, sec. Tech, http://www.wsj.com/articles/fight-over-flickrs-use-of-photos-1416875564.

27 “Flickr Apologizes but What About CC Abuses by Others?," accessed December 7, 2016, http://www.artists-bill-of-rights.org/news/campaign-news/flickr-apologizes-but-whatabout-cc-abuses-by-others?/.

28 “The Terms 'Revocable' and 'Irrevocable' in License Agreements: Tips and Pitfalls," accessed December 7, 2016, http://www.sidley.com/news/the-terms-revocable-and-irrevocable-inlicense-agreements-tips-and-pitfalls-02-21-2013.

29 "Legal Code-Creative Commons," accessed December 7, 2016, https://wiki.creativecommons.org/wiki/Legal_code.

30 "Why CC-BY?_OASPA," accessed December 7, 2016, http://oaspa.org/why-cc-by/.

31 "Why CC-BY?-OASPA."

32 "Intellectual Property Policy," The Andrew W. Mellon Foundation, accessed July 28, 2019, https://mellon.org/grants/grantmaking-policies-and-guidelines/grantmakingpolicies/intellectual-property-policy/.

33 "Why I'm Giving up on Creative Commons on YouTube," Eddie.com, September 6, 2014, http://eddie.com/2014/09/05/why-im-giving-up-on-creative-commons-on-youtube/.

34 "Creative Commons-Attribution 4.0 International-CC BY 4.0," accessed December 7, 2016, https://creativecommons.org/licenses/by/4.0/.

35 "Why I'm Giving up on Creative Commons on YouTube." 
36 "Creative Commons-Attribution 4.0 International-CC BY 4.0."

37 "Why I'm Giving up on Creative Commons on YouTube."

38 "Creative Commons-Attribution 4.0 International-CC BY 4.0."

${ }^{39}$ Ibid.

40 “CC Search," accessed December 7, 2016, https://search.creativecommons.org/.

41 "Creative Commons-Attribution-NonCommercial-ShareAlike 4.0 International-CC BY-NC-SA 4.0," accessed December 7, 2016, https://creativecommons.org/licenses/by-ncsa/4.0/legalcode.

42 “U.S. Copyright Office Fair Use Index,” U.S. Copyright Office, accessed April 21, 2019, https://www.copyright.gov/fair-use/.

${ }^{43}$ Ibid.

${ }^{44}$ Ibid.

${ }^{45}$ Jerry D Campbell, "Intellectual Property in a Networked World: Balancing Fair Use and Commercial Interests," Library Acquisitions: Practice and Theory 19, no. 2 (1995): 179-84, https://doi:10.1016/0364-6408(95)00020-A; Igor Slabykh, "Ambiguous Commercial Nature of Use in Fair Use Analysis," AIPLA Quarterly Journal 46, no. 3 (2018): 293-339.

46 "Defending Noncommercial Uses: Great Minds v Fedex Office," Creative Commons, August 30, 2016, https://creativecommons.org/2016/08/30/defending-noncommercial-uses-greatminds-v-fedex-office/.

47 "Princeton University Press v. Michigan Document Services," Bitlaw, accessed December 7, 2016, http://www.bitlaw.com/source/cases/copyright/pup.html\#IIIA.

${ }^{48}$ Justia, "Great Minds v. FedEx Office \& Print Services, Inc," Stanford Copyright and Fair Use Center, March 21, 2018, https://fairuse.stanford.edu/case/great-minds-v-fedex-office-printservices-inc/.

${ }^{49}$ Minjeong Kim, "The Creative Commons and Copyright Protection in the Digital Era: Uses of Creative Commons Licenses," Journal of Computer-Mediated Communication 13, no. 1 (2007): 187-209, https://doi:10.1111/j.1083-6101.2007.00392.x; "Directory of Open Access Journals," DOAJ, accessed December 1, 2016, https://doaj.org.

50 "FEATURE: Creative Commons: Copyright Tools for the 21st Century," accessed December 7 , 2016, http://www.infotoday.com/online/jan10/Gordon-Murnane.shtml.

51 "The Creative Commons and Copyright Protection in the Digital Era: Uses of Creative Commons Licenses."

${ }^{52}$ Ibid. 
53 "Creative Commons-Attribution-ShareAlike 4.0 International-CC BY-SA 4.0," accessed December 7, 2016, https://creativecommons.org/licenses/by-sa/4.0/legalcode\#s6a.

54 “17 U.S. Code § 101—Definitions," Legal Information Institute, accessed April 20, 2019, https://www.law.cornell.edu/uscode/text/17/101.

55 "Creative Commons-Attribution-NonCommercial-NoDerivatives 4.0 International-CC BY-NCND 4.0," accessed December 7, 2016, https://creativecommons.org/licenses/by-ncnd/4.0/legalcode.

56 "Creative Commons-Attribution-NonCommercial-NoDerivatives 4.0 International-CC BY-NCND 4.0."

${ }^{57}$ The famous Campbell v. Acuff-Rose Music case established that a commercial parody could qualify as fair use.

${ }^{58} \mathrm{Katz}$, "Pitfalls of Open Licensing," 411.

59 "Professional Ethics," Tools, Publications \& Resources, American Library Association, February 6, 2019, http://www.ala.org/tools/ethics.

60 "Creative Commons-Attribution-ShareAlike 4.0 International-CC BY-SA 4.0," accessed December 7, 2016, https://creativecommons.org/licenses/by-sa/4.0/.

${ }^{61}$ Molly Houweling, “The New Servitudes," Georgetown Law Journal 96, no. 3 (2008): 885-950.

62 “Compatible Licenses," Creative Commons, accessed December 7, 2016, https://creativecommons.org/share-your-work/licensing-considerations/compatiblelicenses/.

${ }^{63}$ Katz, "Pitfalls of Open Licensing," 391; Susan Corbett, "Creative Commons Licences, the Copyright Regime and the Online Community: Is There a Fatal Disconnect?," The Modern Law Review 74, no. 4 (2011): 506, http://www.jstor.org/stable/20869091.

${ }^{64}$ Lawrence Lessig, "Against Transparency," New Republic, October 8, 2009, https://newrepublic.com/article/70097/against-transparency.

65 "Creative Commons CEO Apologizes To Virgin Mobile-Stock Photography News, Analysis and Opinion," accessed December 7, 2016, https://www.selling-stock.com/Article/creativecommons-ceo-apologizes-to-virgin-mob.

66 "Frequently Asked Questions," Creative Commons, accessed July 30, 2019, https://creativecommons.org/faq/\#how-are-publicity-privacy-and-personality-rightsaffected-when-i-apply-a-cc-license.

67 "Defending Noncommercial Uses: Great Minds v Fedex Office," Creative Commons, August 30, 2016, https://creativecommons.org/2016/08/30/defending-noncommercial-uses-greatminds-v-fedex-office/. 
${ }^{68}$ Andrea Malone et al., "Center Stage: Performing a Needs Assessment of Campus Research Centers and Institutes," Journal of Library Administration 57, no.4 (2017): 406-19, https://doi:10.1080/01930826.2017.1300451.

${ }^{69}$ Laura Gordon-Murnane, "FEATURE: Creative Commons: Copyright Tools for the 21st Century,” Information Today, accessed December 7, 2016,

http://www.infotoday.com/online/jan10/Gordon-Murnane.shtml.

70 Ibid. 